\title{
Role of Platelet-Derived Growth Factor-CC in Capillary Rarefaction in Renal Fibrosis
}

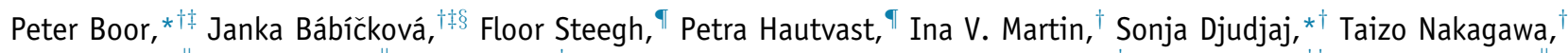
Josef Ehling, ${ }^{\|}$Felix Gremse, ${ }^{\|}$Eva Bücher, ${ }^{\dagger}$ Ulf Eriksson, ${ }^{* *}$ Claudia R.C. van Roeyen, ${ }^{\dagger}$ Frank Eitner, ${ }^{\dagger \dagger}$ Twan Lammers, Jürgen Floege, ${ }^{\dagger}$ Carine J. Peutz-Kootstra, ${ }^{\top}$ and Tammo 0stendorf ${ }^{\dagger}$

From the Institute of Pathology, ${ }^{*}$ the Division of Nephrology, ${ }^{\dagger}$ and the Department of Experimental Molecular Imaging, ${ }^{\| W T H}$ Aachen University, Aachen, Germany; the Institute of Molecular Biomedicine, ${ }^{\ddagger}$ Comenius University, Bratislava, Slovakia; the Center for Molecular Medicine, ${ }^{\S}$ Slovak Academy of Sciences, Bratislava, Slovakia; the Institute of Pathology, "Maastricht University, Maastricht, the Netherlands; the Department of Medical Biochemistry and Biophysics, ${ }^{* *}$ Karolinska Institutet, Stockholm, Sweden; and Bayer Healthcare, ${ }^{\dagger \dagger}$ Wuppertal, Germany

Accepted for publication April 21, 2015.

Address correspondence to Peter Boor, M.D., Ph.D., Institute of Pathology and Division of Nephrology, University Clinic of the RWTH Aachen University, Pauwelsstrasse 30, D-52074 Aachen, Germany. E-mail: pboor@ukaachen.de.

\begin{abstract}
We have identified platelet-derived growth factor (PDGF)-CC as a potent profibrotic mediator in kidney fibrosis and pro-angiogenic mediator in glomeruli. Because renal fibrosis is associated with progressive capillary rarefaction, we asked whether PDGF-CC neutralization in fibrosis might have detrimental anti-angiogenic effects leading to aggravated peritubular capillary loss. We analyzed capillary rarefaction in mice with and without PDGF-CC neutralization (using genetically deficient mice and neutralizing antibodies), in three different models of renal interstitial fibrosis, unilateral ureteral obstruction, unilateral ischemia-reperfusion, Col4a3-deficient (Alport) mice, and healthy animals. Independent of the effect of PDGF-CC neutralization on renal fibrosis, we found no difference in capillary rarefaction between PDGF-CC-neutralized mice and mice with intact PDGF-CC. We also found no differences in microvascular leakage (determined by extravasation of Evans Blue Dye) and in renal relative blood volume quantified using in vivo microcomputed tomography. PDGFCC neutralization had no effects on renal microvasculature in healthy animals. Capillary endothelium did not express PDGF receptor- $\alpha$, suggesting that potential PDGF-CC effects would have to be indirect. PDGF-CC neutralization or deficiency was not associated with preservation or accelerated loss of peritubular capillaries, suggesting no significant pro-angiogenic effects of PDGF-CC during renal fibrosis. From a clinical perspective, the profibrotic effects of PDGF-CC outweigh the pro-angiogenic effects and, thus, do not limit a potential therapeutic use of PDGF-CC inhibition in renal fibrosis. (Am J Pathol 2015, 185: 2132-2142; http://dx.doi.org/10.1016/j.ajpath.2015.04.022)
\end{abstract}

Renal fibrosis is the underlying pathological process of progressive kidney diseases. One of the hallmarks of renal fibrosis is the rarefaction of peritubular capillaries (PTCs). The loss of capillaries was proposed to be not only an important factor in progression of fibrosis (via aggravation of hypoxia), but was also suggested to be a trigger for fibrosis induction under certain conditions. ${ }^{1,2}$ Molecules involved in this process are not well characterized. For example, one of the prototypic proangiogenic molecules, vascular endothelial growth factor (VEGF), was shown to have context-dependent effects, being antifibrotic or profibrotic depending on models and manipulations used. ${ }^{3,4}$

Platelet-derived growth factor (PDGF)-CC is a potent profibrotic factor in the kidney. Genetic PDGF-C deficiency or neutralizing antibodies reduced renal interstitial fibrosis in mice with unilateral ureteral obstruction (UUO). ${ }^{5}$ Several studies showed that PDGF-CC is also a potent, VEGF-independent, pro-angiogenic factor (eg, in the heart, muscle, or eye), and PDGF-CC inhibition was suggested as a novel anti-angiogenic therapy in pathological angiogenesis..$^{6-10}$ The pro-angiogenic role of PDGF-CC was confirmed in experimental models of

\footnotetext{
Supported by Deutsche Forschungsgemeinschaft grants P25, P17, and Q1 of the SFB/Transregio 57 Mechanisms of Organ Fibrosis (P.B., J.F., and T.O.) and BO 3755/1-1 and BO 3755/2-1 (P.B.), Else-Kröner Fresenius Stiftung grant EKFS 2012_A216 (P.B.), the START-Program (124/14) of the Faculty of Medicine, RWTH Aachen University, the Interdisciplinary Center for Clinical Research within the Faculty of Medicine at the RWTH Aachen University (E6-10; T.O. and J.F.) and (K7-3; P.B. and J.F.); and the Profileringsfonds of the academic Hospital Maastricht (C.J.P.-K.).

Disclosures: F.E. is an employee of Bayer Healthcare.
} 
glomerular diseases in which PDGF-CC infusion promoted and PDGF-CC inhibition disrupted glomerular capillary healing. ${ }^{11}$ Consistent with previous studies, ${ }^{6-8}$ these pro-angiogenic effects were both direct, inducing endothelial cell proliferation, and indirect, inducing production of pro-angiogenic molecules in various cell types. ${ }^{11}$

Herein, we analyzed the question resulting from these experiments, namely whether PDGF-CC also exerts proangiogenic effects in the renal interstitium during renal fibrosis.

\section{Materials and Methods}

\section{In Vivo Experiments}

For these experiments, we reanalyzed the tissues from previously published experiments using mice with UUO (days 5 and 10), genetically deficient for PDGF-CC (PDGF-CC ${ }^{--}$), versus wild-type littermates $\left(\mathrm{PDGF}_{-} \mathrm{CC}^{+/+}\right.$), or those treated with PDGF-CC-neutralizing antibodies (PDGF-CC antibody) versus isotype-matched $\mathrm{IgG}$.

Ischemia-reperfusion injury (I/R) was performed by left lateral incision. Both renal vein and renal artery were clamped with a microserrefine (Fine Science Tools GmbH, Heidelberg, Germany) for 30 minutes. The ischemia and subsequent reperfusion were checked macroscopically. All operations were performed on a heating pad set to $37^{\circ} \mathrm{C}$ (warm ischemia), and body temperature was measured rectally throughout the kidney ischemia (TC-1000 Temperature Controller; CWE, Ardmore, PA). Sham-operated on mice underwent the same procedure without clamping the vessels. Ischemia was induced in PDGF$\mathrm{CC}^{+/+}(n=12)$ and PDGF-CC ${ }^{-/-}(n=6)$ mice or in mice treated with $10 \mathrm{mg} / \mathrm{kg}$ body weight PDGF-CC-neutralizing antibody $(n=13)$ or $10 \mathrm{mg} / \mathrm{kg}$ body weight isotype-matched control $\operatorname{IgG}(n=12)$, on days 1,3 , and 5 after disease induction and twice weekly thereafter. Mice were sacrificed on day 21 after the surgery (unpublished data, T.N. and I.V.M.).

In addition, healthy PDGF-CC ${ }^{-/-}$mice $(n=8)$ and PDGF-CC ${ }^{+/+}$littermates $(n=5)$ and healthy $\mathrm{C} 57 \mathrm{Bl} / 6$ mice treated with PDGF-CC-neutralizing antibody $(n=3,10$ $\mathrm{mg} / \mathrm{kg}$ body weight, twice weekly i.p. for 3 weeks) versus un-specific $\operatorname{IgG}(n=3,10 \mathrm{mg} / \mathrm{kg}$ body weight, twice weekly i.p. for 3 weeks) were analyzed (all between 10 and 12 weeks old).

Alport mice were crossbred with $\mathrm{PDGF}^{-\mathrm{C}^{-/}}$mice, and PDGF-C $^{-/-}$or PDGF-C ${ }^{+/+}$Alport mice were sacrificed at the age of 10 weeks. Six-week-old male Alport mice were treated twice weekly via i.p. injection of PDGF-CC-neutralizing antibody or isotype-matched $\mathrm{IgG}(10 \mathrm{mg} / \mathrm{kg}$ body weight $)$ for 3 weeks (unpublished data, C.R.C.vanR.).

For functional analysis of renal microvasculature [ie, extravasation of Evans Blue Dye and contrast-enhanced in vivo microcomputed tomography (CT) analysis of renal relative blood volume (rBV); see below], PDGF-CC ${ }^{-1-}$ mice and PDGF-CC $^{+/+}$littermates with UUO day 5 were compared (see below). The UUO was performed in a standardized manner, as previously described. ${ }^{5,12}$ Briefly, after abdominal midline incision, the left ureter was ligated and cut in between the ligatures to avoid ascending infection. The wound was sutured in two layers.

\section{Measurement of Microvascular Permeability}

Microvascular permeability was measured using a modified and optimized protocol (unpublished data, J.B.), as described by Yamaguchi et al. ${ }^{13}$ This method is based on high-affinity binding of the Evans Blue Dye to plasma albumin, ${ }^{14,15}$ which extravasates to the interstitial space only if the microvasculature becomes leaky and is a sensitive marker of microvascular leakage. ${ }^{16}$ In brief, Evans Blue Dye (Sigma-Aldrich, Steinheim, Germany) was dissolved in $0.9 \% \mathrm{NaCl}(5 \mathrm{mg} / \mathrm{mL})$ and applied to anesthetized mice i.v. via the tail vein $(10 \mu \mathrm{g} / \mathrm{g}$ body weight). After 35 minutes, the mice were perfused with $40 \mathrm{~mL}$ of $0.9 \% \mathrm{NaCl}$ applied through the left ventricle of the heart, with particular focus on consistency and thoroughness of the perfusion. The kidneys were then extracted and cut into two halves longitudinally. Half of each kidney was weighed and incubated in $100 \%$ formamide ( $4 \mathrm{~mL} / \mathrm{g}$ kidney weight) at $56^{\circ} \mathrm{C}$ for 12 hours. The extracted dye was measured spectrophotometrically at $620 \mathrm{~nm}$. The results are expressed as $\mu \mathrm{g} / \mathrm{g}$ kidney weight. The other half of the kidneys was used to confirm induction of fibrosis and capillary rarefaction, which, as expected, was observed in all mice (data not shown).

For these experiments, 11 UUO mice [for PDGF-CC ${ }^{-/-}$ $(n=5)$ and PDGF-CC $\left.{ }^{+/+}(n=6)\right]$ and 8 healthy mice PPDGF-CC $^{-/-}(n=5)$ and PDGF-CC ${ }^{+/+}(n=3)$ ] were used.

\section{In Vivo $\mu \mathrm{CT}$ Imaging}

To quantify noninvasively the $\mathrm{rBV}$ in kidneys of PDGF-CC ${ }^{-1-}$ $(n=3)$ and PDGF-CC ${ }^{+/+}(n=3)$ mice with UUO day 5 , contrast-enhanced in vivo $\mu \mathrm{CT}$ was performed, as described previously, ${ }^{17,18}$ and adopted for kidneys (unpublished data, J.E.). The accuracy and congruency of this novel contrastenhanced in vivo $\mu \mathrm{CT}$ imaging technique were already proved previously for quantifying vascularization in tumor xenografts and experimental models for liver fibrosis in mice. ${ }^{17,18}$ In brief, mice were anesthetized with $1.5 \%$ isoflurane in oxygen-enriched air and imaged before and after i.v. injection of $100 \mu \mathrm{L}$ iodine-containing contrast agent eXIATM160XL (Binitio Biomedical, Ottawa, ON, Canada) using a TomoScope 30s Duo $\mu \mathrm{CT}$ scanner (CT Imaging, Erlangen, Germany) at 41 and $65 \mathrm{kV}$. A Feldkamp-type reconstruction algorithm (CT Imaging), including ring artifact correction, was performed, resulting in a voxel side length of $35 \mu \mathrm{m}$. Reconstructed data were analyzed using Imalytics Preclinical software version 3.2 (Philips Research, Aachen, Germany).

The rBV was calculated as the average brightness of the renal cortex after contrast agent injection, the aorta as a reference blood vessel after contrast agent injection $(100 \% \mathrm{rBV})$, and the renal cortex before contrast agent administration $(0 \% \mathrm{rBV}){ }^{19}$ 
Table 1 List of Primers Used for Real-Time RT-PCR Using SYBR Green in the Study

\begin{tabular}{|c|c|c|}
\hline Gene & Forward primer & Reverse primer \\
\hline Vegfa & 5'-TCTTCAAGCCGTCCTGTGTG-3' & 5'-CTCCAGGGCTTCATCGTTACA-3' \\
\hline Flt1 & 5'-CTGTCCATGAAAGTGAAGGCC-3' & 5'-CATGTACCAAATAGCGAGCAGACT-3' \\
\hline$K d r$ & 5'-TGGATTCCTACCAGTATGGGACC-3' & 5'-TCTAGCTGCCAGTACCACTGGA-3' \\
\hline Fgf2 & $5^{\prime}-$ CCGCGTGGATGGCGTC- $3^{\prime}$ & 5'-ССтстстстTCTGCTTGGAGTTG-3' \\
\hline Angpt1 & 5'-CTGAATGGGATAAAGTGGCACTACT-3' & $5^{\prime}-\mathrm{TCCAAGGGCCGGATCAT-3^{ \prime }}$ \\
\hline Angpt2 & $5^{\prime}-\mathrm{ATGACCTAATGGAGACCGTCAAC-3^{ \prime }}$ & 5'-AGTCTCTGAAGGTGGTTTGCTCTT-3' \\
\hline
\end{tabular}

For this purpose, five representative volumes of interest (each $500 \mu^{3}$ ) were analyzed per kidney cortex.

\section{Renal Morphology and Immunohistochemistry}

Tissues for light microscopy and immunohistochemistry were fixed in methyl Carnoy's solution and embedded in paraffin, and sections (1 $\mu \mathrm{m}$ thick) were stained and processed as previously described. ${ }^{5,11,12,20}$ All histomorphological analyses were performed in a blinded manner (P.B., J.B., P.H., and F.S.).

Monoclonal rat anti-mouse MECA-32 antibody was purchased from Developmental Studies Hybridoma Bank (The University of Iowa, Iowa City, IA) and used in a dilution of 1:250, and rabbit monoclonal anti-human PDGFR receptor (PDGFR)- $\beta$ antibody, clone Y92 (Abcam, Cambridge, MA) was purchased and used in a dilution of 1:100. Biotinylated secondary antibodies were purchased from Vector Laboratories (Burlingame, CA). For negative controls, instead of primary antibodies, phosphate-buffered saline (PBS) buffer or irrelevant matched IgG was used, and no un-specific staining was observed (data not shown).

To analyze renal microvasculature, we first tested several immunohistochemical protocols using CD31, VEGF receptor-2, and MECA-32 antibodies. All antibodies marked specifically PTCs, but because the latter performed best (data not shown), for all the following experiments, we have used MECA-32 staining for PTC analyses. The analysis of PTC was performed as described previously, and the data are given as fold change compared with untreated or wild-type mice. ${ }^{20}$ Morphometry was performed using an image processing and analysis system (Qwin Leica; Leica, Cambridge, UK), linked to a Leica DML3000 light microscope. Images were obtained with a $40 \times$ objective by one blinded observer (P.H.). Per slide, 10 to 20 images of cortex were analyzed, and the number of PTCs was counted by two blinded observers (P.H. and F.S.).

\section{Immunofluorescence Double Staining}

Double-immunofluorescence staining for MECA-32 and PDGFR- $\alpha$ as well as CD31 and Ki-67 was performed in methyl Carnoy's solution-fixed, paraffin-embedded, xylenedeparaffinized, and graded ethanol-dehydrated sections. Monoclonal rabbit anti-human PDGFR- $\alpha$, clone D1E1E, was purchased from Cell Signaling Technology Inc. (Danvers, MA; 1:50 dilution). For the analyses of proliferating endothelial cells, instead of MECA-32, we used anti-CD31 antibody to stain the endothelium because this was compatible with Ki-67 antibody for the double immunofluorescence. Rat monoclonal anti-mouse CD31 antibody, clone SZ31, was obtained from Dianova (Hamburg, Germany; 1:20 dilution), and rabbit monoclonal anti-human Ki-67 antibody, clone SP6, was purchased from Abcam (1:150 dilution). Primary antibodies were diluted in PBS containing 1\% bovine serum albumin (Sigma-Aldrich), applied simultaneously, and incubated for 1 hour. After washing with PBS $(2 \times)$, secondary antibodies (goat anti-rat Alexa-647 and goat anti-rabbit Alexa-488; Molecular Probes, Leiden, the Netherlands) were applied simultaneously and incubated for 30 minutes. After washing with PBS $(2 \times), 1 \mu \mathrm{g} / \mathrm{mL}$ DAPI was applied for 10 minutes, washed with PBS $(2 \times)$, and mounted with Immu-Mount (Thermo Fischer Scientific, Rockford, IL). The immunofluorescence was analyzed using confocal laserscanning microscope LSM710 from Leica and immunofluorescence microscope BZ9000 from Keyence (Osaka, Japan). PBS buffer or irrelevant matched IgG, instead of primary antibodies, was used as a negative control; both were negative.

\section{RNA Extraction and Analysis}

Total RNA was extracted from isolated murine renal cortex using the RNeasy Mini Kit (Qiagen, Hilden, Germany). cDNA syntheses and real-time quantitative PCRs were performed as previously described. ${ }^{5,11}$ In short, the concentration and the purity of RNA were measured spectrophotometrically using Nanodrop (NanoDrop Technologies, Wilmington, DE). For real-time PCR, the Qiagen QuantiFast SYBR Green RT-PCR kit (Qiagen) was used according to the manufacturer's instructions. For normalization of the data, the standard $\Delta \mathrm{Ct}$ method was used with Gapdh as the housekeeping gene. The expression of the genes of interest was calculated as relative fold change in expression in comparison to the appropriate control group, arbitrarily set as 1 . Sequences of primers and probes are given in Table 1.

\section{Statistical Analysis}

Data are presented as means \pm SD. By using GraphPad Prism Version 5.03 (La Jolla, CA), one-way analysis of variance with Bonferroni post hoc analysis or $t$-test was used, where appropriate, to evaluate the results. $P<0.05$ was considered significant. 
A

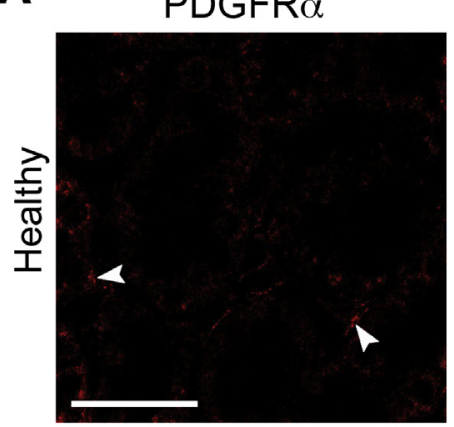

B

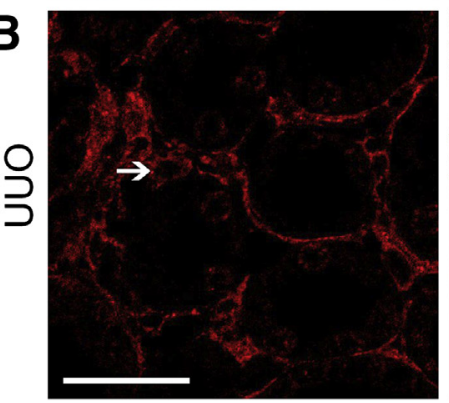

Meca32
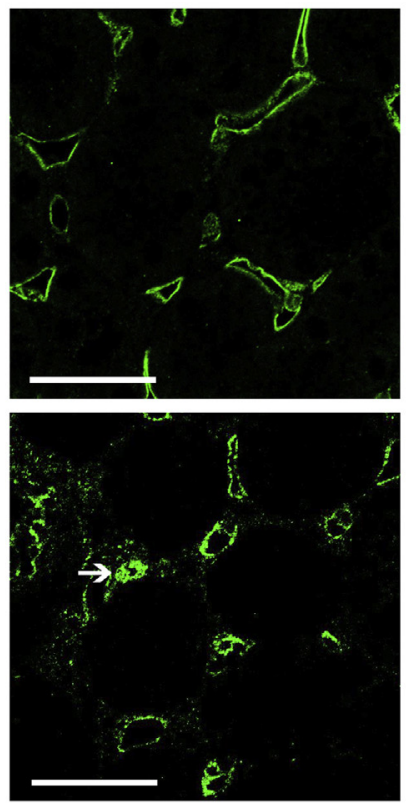

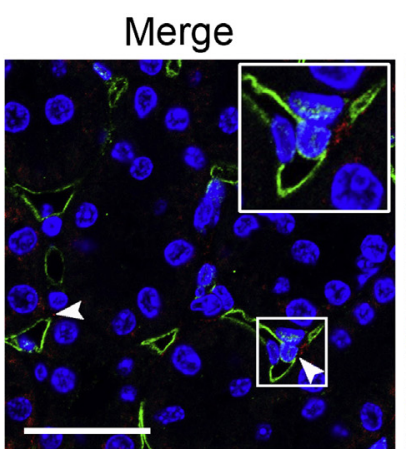

Transmission Overlay
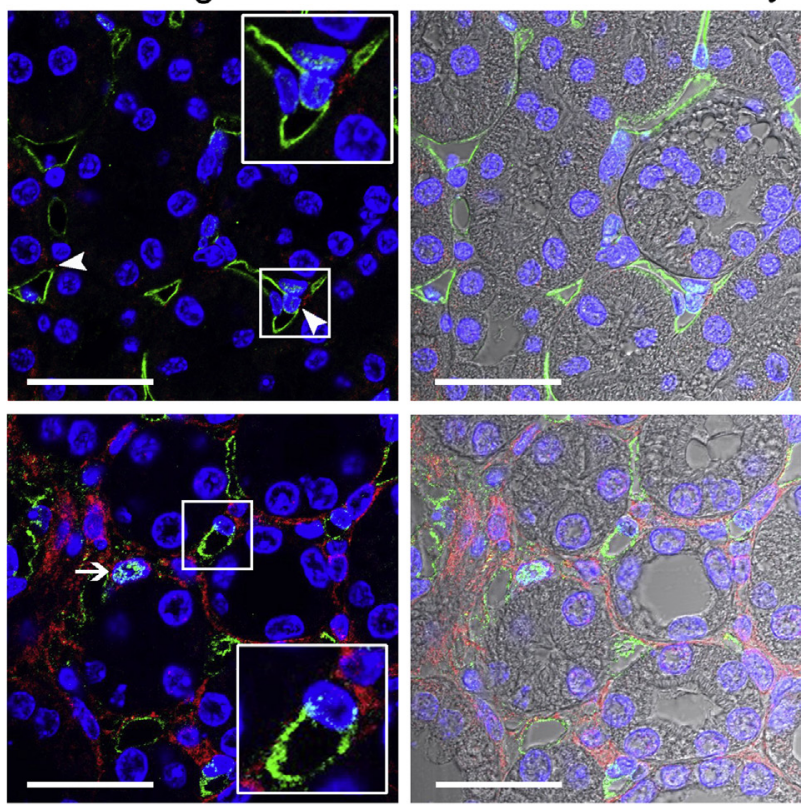

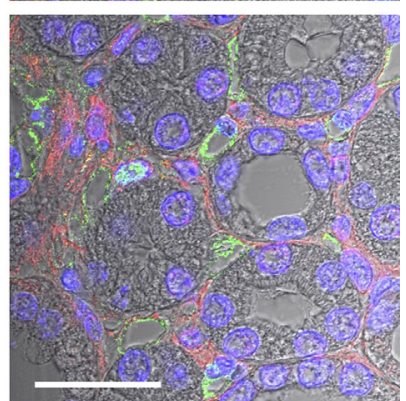

C

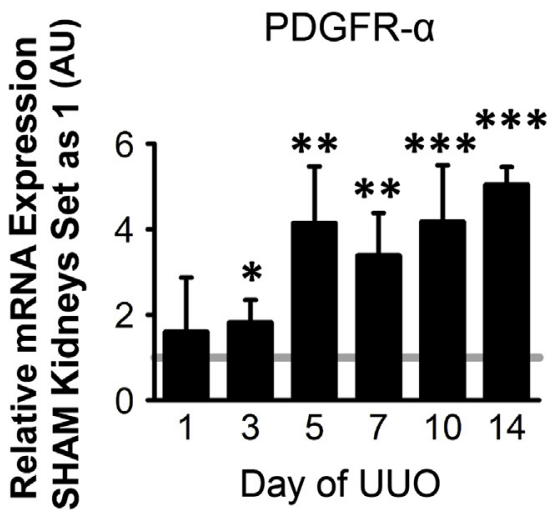

Figure 1 Platelet-derived growth factor receptor (PDGFR)- $\alpha$ is up-regulated in renal fibrosis and shows almost virtually exclusive localization with mouse endothelial cell antigen (MECA)-32. A: In healthy controls, only minimal expression of PDGFR- $\alpha$ (red) in the interstitium (arrowheads) is observed. No expression in endothelial cells colocalizing with MECA-32 (green) are found; nuclei were counterstained with blue/DAPI antigen. B: Unilateral ureteral obstruction (UU0) shows massive overexpression of PDGFR- $\alpha$ in the interstitium. Mostly, areas of virtually exclusive staining with MECA-32 are observed, and only scarce areas of endothelial expression of PDGFR- $\alpha$ are found (arrows). Insets: A digital magnification of the areas outlined with squares. C: $m R$ RNA analysis shows a gradual increase of the renal expression of PDGFR- $\alpha$ during UUO progression (gray line is expression in shamoperated on kidneys, set as 1 ). Data are means \pm SD. ${ }^{*} P<0.05,{ }^{* *} P<0.01$, and $* * * P<0.001$ versus sham. Scale bar $=10 \mu \mathrm{m}(\mathbf{A}$ and $\mathbf{B})$.

\section{Results}

\section{PDGFR- $\alpha$ Expression on Endothelial Cells of PTCs}

We first analyzed the expression of PDGF receptor (PDGFR)$\alpha$, the receptor of PDGF-CC, by immunofluorescence using confocal laser-scanning microscopy (Figure 1, A and B). As expected, it was specifically expressed in the interstitium and markedly up-regulated in mice with UUO. Colocalization of PDGFR- $\alpha$ and MECA-32 showed mutually exclusive staining in the healthy kidneys (Figure 1A) and also in the fibrotic kidneys (Figure 1B). However, in small areas, some endothelial PDGFR- $\alpha$ expression could be observed (Figure 1B). Expression of cortical PDGFR- $\alpha$ was significantly increased after induction of UUO on the mRNA level (Figure 1C).

PDGF-CC Neutralization Does Not Alter the Number of PTCs in Healthy Mice

In healthy animals, no significant differences in the number of PTCs were observed between IgG-treated and PDGF-CC antibody-treated mice (Figure 2A). Similarly, no significant differences were observed between PDGF-CC ${ }^{+/+}$and PDGF-CC $^{-/-}$mice (Figure 2B). In addition, a comparison of the contralateral nonfibrotic kidneys revealed no differences in number of PTCs between IgG-treated and PDGF-CC antibody-treated mice neither in the UUO day 5 group $(1.00 \pm 0.02$ versus $0.96 \pm 0.08)$ nor in the UUO day 10 group $(1.00 \pm 0.05$ versus $0.99 \pm 0.07)$ or the $\mathrm{I} / \mathrm{R}$ day 21 group $(1.00 \pm 0.10$ versus $0.92 \pm 0.06)$.

PDGF-CC Neutralization Does Not Alter the Number of PTCs in Three Different Models of Renal Fibrosis

As previously demonstrated, genetic deficiency of PDGF-CC resulted in a significant reduction of renal fibrosis on both days 5 and 10 of UUO, whereas treatment with PDGF-CC-neutralizing antibody resulted in a significant reduction of renal fibrosis only on day 5, but not day $10 .{ }^{5}$ Expression of cortical PDGFR- $\beta$, a marker of interstitial fibroblasts and myofibroblasts, was reduced in mice treated with PDGF-CC antibody versus IgG on 
A

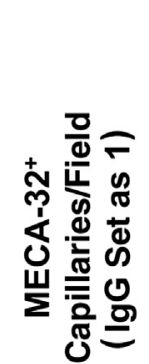

B

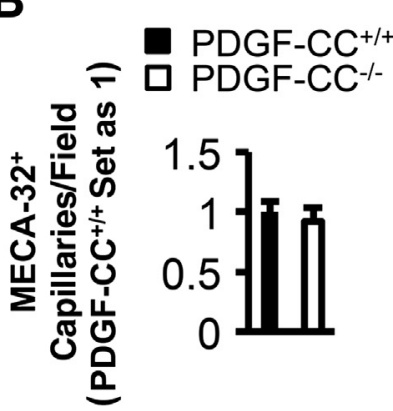

Healthy Baseline
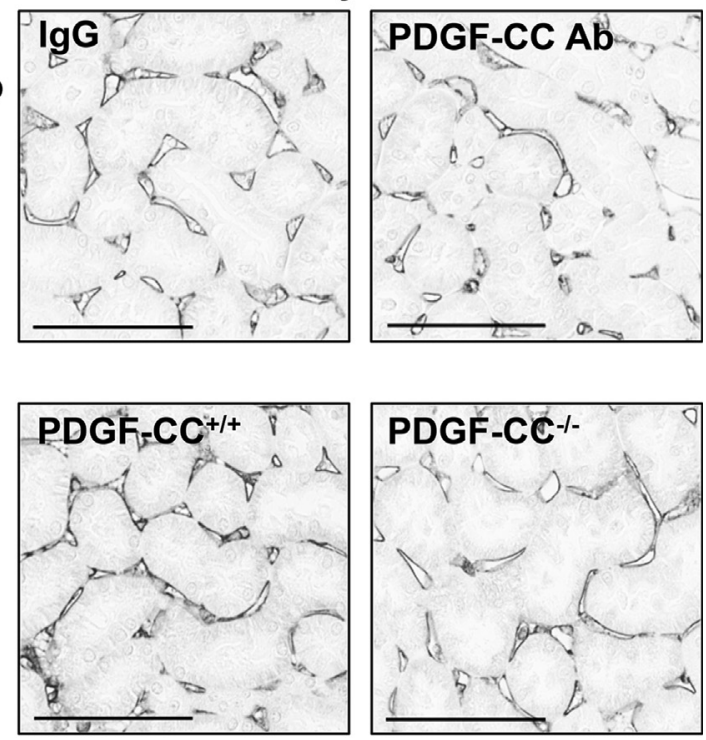

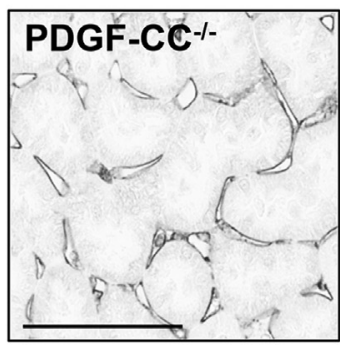

Figure 2 Deficiency of platelet-derived growth factor (PDGF)-CC does not alter the number of peritubular capillaries (PTCs) in healthy mice. The number of PTCs was analyzed in healthy IgG $(n=3)$ or PDGF$\mathrm{CC}$ antibody $(\mathrm{Ab})$-treated $(n=3)$ and healthy wildtype PDGF-CC ${ }^{+/+}(n=8)$ and PDGF-CC ${ }^{-/-}(n=5)$ mice. No significant differences in the number of PTCs are found between control IgG and PDGF-CC antibody-treated mice $(\mathbf{A})$, or between PDGF-CC ${ }^{+/+}$ and PDGF-CC ${ }^{-/-}$mice (B). Data are means \pm SD. Scale bar $=100 \mu \mathrm{m}$ (A and $\mathbf{B})$. MECA, mouse endothelial cell antigen. day 5, but not on day 10 , of UUO, confirming our previous results in these mice (Supplemental Figure S1). The quantification of PTCs showed no significant difference between $\operatorname{IgG}$ and PDGF-CC antibody-treated mice on day 5 of UUO (Figure 3A). Compared with PDGF-CC ${ }^{+/+}$mice, obstructed kidneys of PDGF-CC ${ }^{-\prime-}$ mice had marginally, but significantly, more PTCs (19\%) (Figure 3B). On day 10 of UUO, however, no significant differences in the number of PTCs in the obstructed kidneys were found in either experiment (ie, PDGF-CC antibody versus $\mathrm{IgG}$-treated mice) (Figure 3C) or PDGF-CC ${ }^{+/+}$ versus PDGF-CC ${ }^{-1-}$ mice (Figure $3 \mathrm{D}$ ). In addition, we found no significant differences in proliferation of endothelial cells of PTCs on day 5 of UUO between PDGF-CC-deficient and antibody-treated mice versus WT or IgG-treated mice, respectively (Figure 3, E and F).

In a model of severe unilateral $\mathrm{I} / \mathrm{R}$ injury leading to fibrosis (day 21), both genetic deficiency of PDGF-CC and treatment with neutralizing antibodies had no effect on renal fibrosis (unpublished data, T.N. and I.V.M.). In these mice, no significant differences in PTCs were observed between PDGF-CC $^{+/+}$and PDGF-CC ${ }^{-1-}$ (Figure 4A) and PDGF$\mathrm{CC}$ antibody versus IgG-treated mice (Figure $4 \mathrm{~B}$ ).

In a third model of Alport mice with progressive renal injury, both genetic deficiency of PDGF-CC and treatment with neutralizing antibodies significantly reduced renal fibrosis and improved renal function (unpublished data, C.R.C.vanR.). Compared with IgG-treated Alports, PDGF-CC antibodytreated Alport mice had significantly higher PTC numbers (Figure 4C), whereas quantification of PTC yielded similar numbers in PDGF-CC ${ }^{+/+}$versus PDGF-CC ${ }^{-1-}$ Alport mice (Figure 4D).

We did not observe a significant correlation between the PTC numbers and fibrosis markers in any of the experiments (Table 2).

\section{PDGF-CC Neutralization Does Not Alter Functional Characteristics of PTCs}

In healthy mice, no significant differences in the extravasation of Evans Blue Dye, a well-established marker of microvascular leakage, were observed between PDGF-CC ${ }^{+/+}$and PDGF-CC ${ }^{-1-}$ mice (Figure 5A). On day 5 of UUO, compared with contralateral kidneys, the obstructed fibrotic kidneys showed a more than threefold increase in microvascular leakiness. However, no significant difference between PDGF-CC $^{+/+}$and PDGF-CC ${ }^{-1-}$ mice was observed, although the PDGF-CC ${ }^{-1-}$ mice showed a tendency toward increased leakage (Figure 5B).

\section{PDGF-CC Neutralization Does Not Alter the Functional} Kidney Vascularization in Vivo

To noninvasively quantify the functional kidney vascularization in vivo, contrast-enhanced in vivo microcomputed tomography $(\mu \mathrm{CT})$ imaging was performed in mice with UUO. On day 5 of UUO, obstructed fibrotic kidneys of both PDGF-CC $^{+/+}$and PDGF-CC ${ }^{-/-}$mice exhibited a significantly lower $\mathrm{rBV}$ compared with contralateral kidneys ( $-49 \%$ and $-43 \%$, respectively) (Figure 6), indicating that renal fibrosis results in reduced tissue vascularization. However, no differences in $\mathrm{rBV}$ were observed between PDGF-CC ${ }^{+/+}$and PDGF-CC ${ }^{-/-}$mice in either contralateral or fibrotic kidneys (Figure 6).

Regulation of Genes Involved in Angiogenesis during Renal Fibrosis and PDGF-CC Neutralization

In healthy animals, the relative gene expression of major genes involved in angiogenesis [ie, Vegfa, Flt1 (encodes VEGF 
receptor-1), $K d r$ (encodes VEGF receptor-2), $F g f 2$ (fibroblast growth factor 2), Angpt1, and Angpt2] was not significantly different in PDGF-CC ${ }^{-1-}$ mice or mice treated with PDGF-CC antibody, compared with PDGF-CC ${ }^{+/+}$or IgG-treated mice, respectively (Figure 7A). On day 5 of UUO, Fgf2 was significantly reduced both by PDGF-CC antibody treatment $\left(-40 \%\right.$ versus $\mathrm{IgG}$ group) and in PDGF-CC ${ }^{-/}$mice $(-80 \%$

A

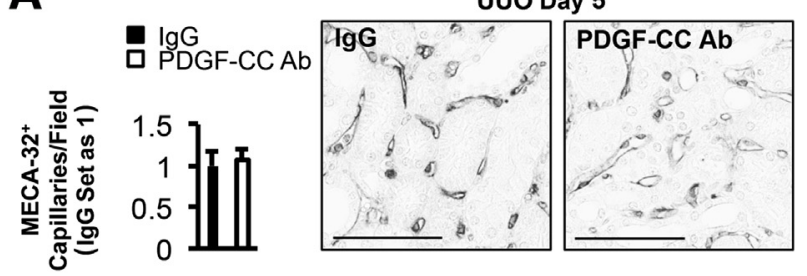

B

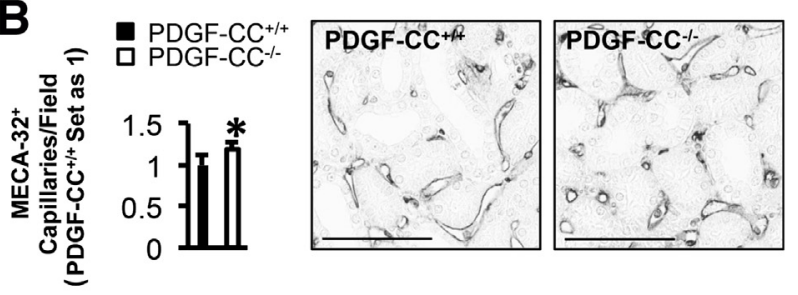

C
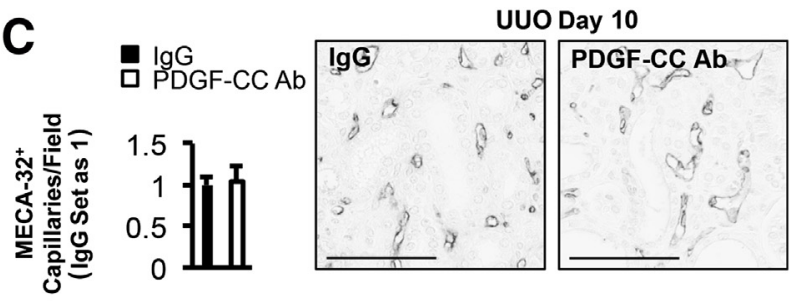

D
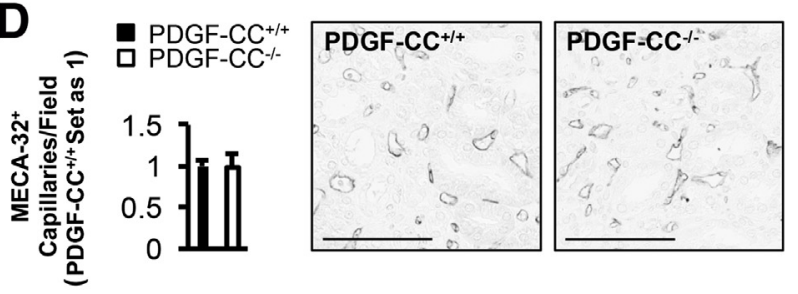

$\mathbf{E}$
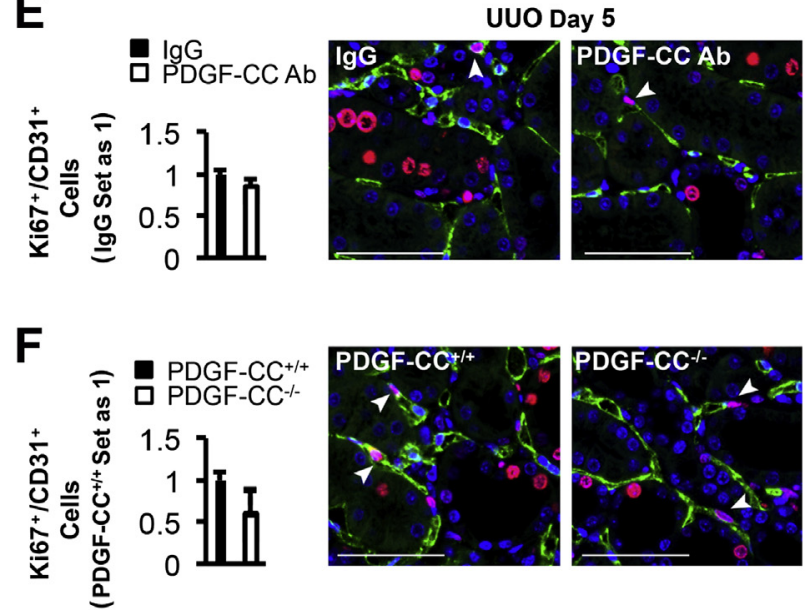

versus PDGF-CC ${ }^{+/+}$) (Figure 7B). The expression of all other analyzed angiogenic genes was similar between $\operatorname{IgG}$ and PDGF-CC antibody-treated mice and PDGF-CC ${ }^{+/+}$and PDGF-CC $^{-/-}$mice (Figure 7B).

On day 21 of $\mathrm{I} / \mathrm{R}$, compared with PDGF-CC ${ }^{+/+}$mice, PDGF-CC $^{-1-}$ mice had significantly higher expression of Vegfa (14\%) and Flt1 (23\%), whereas all of the other genes were comparable between the two groups (Figure 7C).

\section{Discussion}

The major novel finding of our study is that despite the proangiogenic character of PDGF-CC in glomerular diseases, PDGF-CC neutralization had no significant effects on the peritubular microvasculature in healthy animals and, more important, did not significantly aggravate capillary rarefaction during renal fibrosis. These findings from histological and functional analyses were consistent in almost all of the scenarios analyzed (ie, in both genetically PDGF-CC-deficient mice or using a neutralizing PDGF-CC antibody). They were also consistent in all models analyzed: the UUO, the unilateral I/R, and the Alport mice as models of tubulointerstitial fibrosis.

We previously showed that healthy mice genetically deficient for PDGF-CC have an aberrant cerebral microvasculature. ${ }^{21} \mathrm{We}$, therefore, first analyzed whether the renal interstitial microvasculature is affected by PDGF-CC neutralization in healthy mice. Our histomorphological and functional analyses failed to detect any such effects. Similarly, no effects of PDGF-CC deficiency or inhibition on interstitial capillaries in the contralateral unaffected kidneys of the UUO or I/R mice were observed. These data are further supported by our previous findings in acute selflimited rat mesangioproliferative glomerulonephritis, which does not display any overt tubulointerstitial damage. In that model, we also found no effect of PDGF$\mathrm{CC}-$ neutralizing antibody on the interstitial microvasculature. ${ }^{11}$ Taken together, PDGF-CC does not influence the physiological renal microvascular homeostasis in healthy rodents. This supports the notion that in adult mice,

\footnotetext{
Figure 3 Deficiency of platelet-derived growth factor (PDGF)-CC does not alter the number of peritubular capillaries (PTCs) in ureteral obstruction-induced renal fibrosis. PTCs were analyzed at two different time points of unilateral ureteral obstruction (UU0), days 5 and 10, in IgG ( $n=4$ for day 5 and $n=4$ for day 10) versus PDGF-CC antibody-treated mice $\left(n=4\right.$ for day 5 and $n=4$ for day 10) and in PDGF-CC ${ }^{+/+}(n=7$ for day 5 and $n=5$ for day 10) versus PDGF-CC ${ }^{-}-(n=7$ for day 5 and $n=6$ for day 10) mice. No significant differences in the number of PTCs between IgG and PDGF-CC antibody-treated mice are observed on day $5(\mathbf{A})$ or on day 10 (C) of UUO. PDGF-CC ${ }^{-1-}$ mice have significantly more PTCs compared with PDGF-CC ${ }^{+/+}$mice on day 5 (B) but not on day 10 (D) of UUO. The analyses of proliferation of microvascular cortical interstitial endothelial cells using CD31-Ki-67 double immunofluorescence on day 5 of UU0 reveal no significant differences between mice with PDGF-CC antibody treatment (E) or genetic deficiency $(\mathbf{F})$ compared with control IgG treatment or wild-type mice, respectively. Data are means \pm SD. ${ }^{*} P<0.05$ versus PDGF-CC $^{+/+}$or respective contralateral (CONT). Scale bar $=100 \mu \mathrm{m}(\mathbf{A}-\mathbf{F})$.
} 

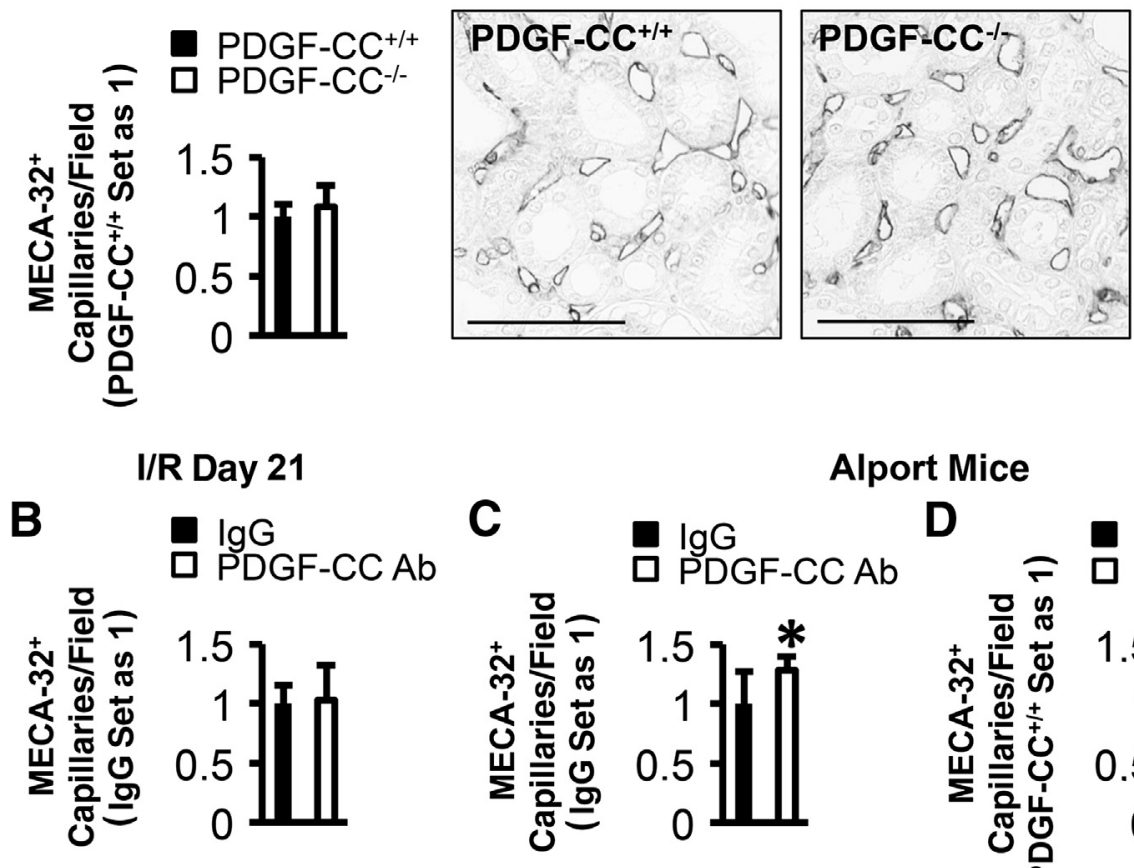

Alport Mice

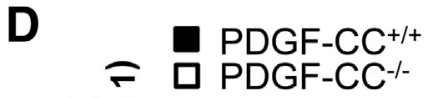

Figure 4 Deficiency of platelet-derived growth factor (PDGF)-CC does not alter the number of peritubular capillaries (PTCs) in postischemic renal fibrosis or in Alport mice. PTCs were also analyzed in postischemic renal fibrosis on day 21 after ischemia-reperfusion injury (I/R) in PDGF-CC $C^{+/+}(n=12)$ versus PDGF$\mathrm{CC}^{-/-}(n=6)(\mathbf{A})$ or in mice treated with neutralizing PDGF-CC antibody (Ab; $\left.n=10\right)$ versus IgG control $(n=9)(\mathbf{B})$. No significant differences in the number of PTCs are observed between these groups. In addition, we also analyzed the Alport mice treated with neutralizing PDGF-CC antibody ( $n=6)$ versus IgG control $(n=4)(C)$ or in PDGF-CC ${ }^{+/+}(n=7)$ versus PDGF-CC ${ }^{-/}(n=4)(D)$. Although PDGF-CC ${ }^{-/-}$and PDGF-CC ${ }^{+/+}$Alport mice have a similar number of PTCs, the antibody-treated mice have significantly higher PTC numbers compared with IgG-treated Alport mice. ${ }^{*} P<0.05$ versus IgG-treated control. Scale bar $=100 \mu \mathrm{m}(\mathbf{A})$. MECA, mouse endothelial cell antigen.

PDGF-CC is involved in angiogenesis in pathological, but not in physiological, instances.

We and others have shown that PDGF-CC is up-regulated in renal fibrosis, in both human biopsy specimens and animal models, including UUO. ${ }^{5,22-25}$ Herein, we have analyzed the expression of the PDGF-CC receptor, PDGFR- $\alpha$, with a particular focus on its potential localization on the endothelium of PTCs. Consistent with previous results, we confirmed the marked up-regulation of PDGFR- $\alpha$ specifically in the tubulointerstitial compartment in fibrotic murine kidneys. ${ }^{24,26-28}$ Our colocalization studies showed that immunoreactivity of the endothelial marker MECA-32 and PDGFR- $\alpha$ was not observed in the same cells, and both markers were mutually exclusive. PDGFR- $\alpha$ only rarely colocalized with MECA-32, suggesting a possible, but low-level, expression of PDGFR- $\alpha$ on endothelium of the PTC (Figure 1), consistent with previous reports in other vascular beds, including our own data in the glomeruli. ${ }^{7,8,11}$ However, these signals could also result from an overlap of endothelium with fibroblasts or pericytes, and further experiments are required to clearly address this issue. Taken together, both the ligand and the receptor are highly up-regulated during renal fibrosis, but because PDGFR- $\alpha$ was not expressed by PTC endothelial cells, any potential pro-angiogenic effect would, therefore, have to be indirect.
PDGF-CC exerts its actions on several cellular targets, and three major mechanisms underlying its pro-angiogenic actions were proposed: i) direct effects on the renal vasculature and microvascular endothelium; ii) effects on stroma

Table 2 Summary of the Animal Experiments and the Effects of PDGF-CC Neutralization on Renal Fibrosis and the Number of PTCs

\begin{tabular}{llll}
\hline Model & Groups & Fibrosis & PTC numbers \\
\hline UU0 day 5 & K0 vs WT & $\downarrow$ & $\uparrow$ \\
UU0 day 5 & Ab vs IgG & $\downarrow$ & $=$ \\
UU0 day 10 & K0 vs WT & $\downarrow$ & $=$ \\
UU0 day 10 & Ab vs IgG & $=$ & $=$ \\
I/R day 21 & K0 vs WT & $=$ & $=$ \\
I/R day 21 & Ab vs IgG & $=$ & $=$ \\
Alport & K0 vs WT & $\downarrow$ & $=$ \\
Alport & Ab vs IgG & $\downarrow$ & $\uparrow$ \\
\hline
\end{tabular}

Renal fibrosis was analyzed using computer-based morphometry of immunohistochemical staining for fibrosis markers (eg, collagen type I, fibronectin, and $\alpha$-smooth muscle actin) and mRNA expression of the same markers (unpublished studies, T.N., I.V.M., C.R.C.vanR.). ${ }^{5}$ Correlation between the fibrosis markers and PTC numbers was performed using univariate regression analyses, and was not significant in any of the experiments.

$\uparrow$, increased; $\downarrow$, decreased; $A b$, neutralizing platelet-derived growth factor (PDGF)-CC antibody; Alport, Col4a3-deficient mice; I/R, unilateral ischemia/reperfusion injury; KO, knockout for PDGF-CC; UUO, unilateral ureteral obstruction; WT, wild type. 

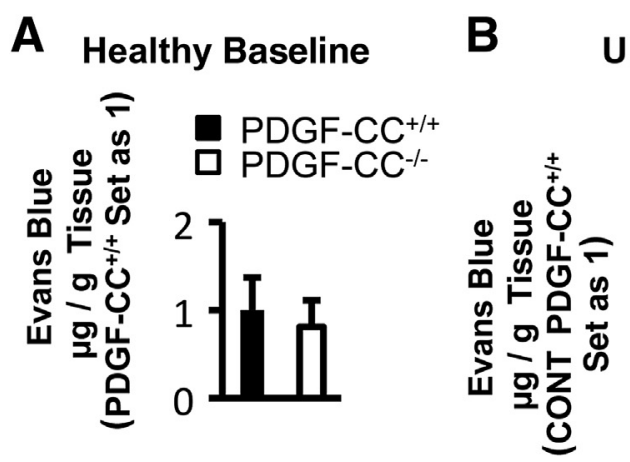

UUO Day 5
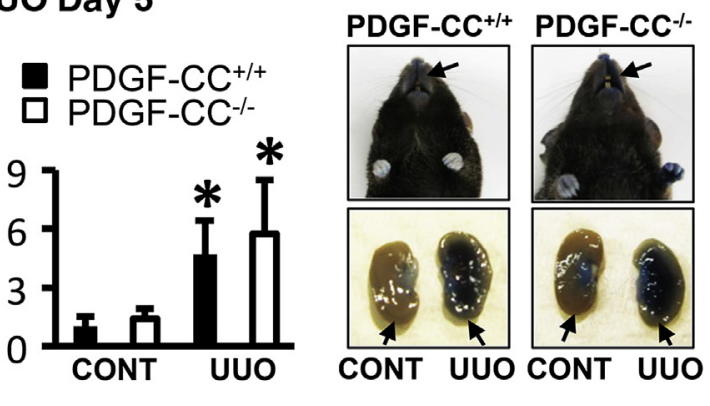

Figure 5 Vascular leakage measured by Evans Blue Dye extravasation is not altered by platelet-derived growth factor (PDGF)-CC deficiency. A: Healthy PDGF-CC ${ }^{+/+}(n=3)$ and PDGF-CC ${ }^{-/-}(n=5)$ mice were analyzed, and no significant differences in vascular leakage were found. B: Macroscopically, mice injected with Evans Blue Dye have a blue nose (arrows), skin, and paws. On day 5 of unilateral ureteral obstruction (UU0), a marked increase of Evans Blue Dye extravasation was found in fibrotic kidneys of both PDGF-CC ${ }^{+/+}(n=6)$ and PDGF-CC ${ }^{-/-}(n=5)$ mice, when compared with contralateral kidneys $(P<0.05$; macroscopic comparison of contralateral versus UUO kidneys). No significant differences in vascular leakage are observed in fibrotic kidneys between PDGF$\mathrm{CC}^{+/+}$and PDGF-CC ${ }^{-/-}$mice. Data are means \pm SD. ${ }^{*} P<0.05$ versus respective contralateral (CONT).

and, in particular, fibroblasts indirectly influencing angiogenesis; and iii) via a switch of inflammatory macrophages toward a pro-angiogenic phenotype. ${ }^{711}$ Given the cellular expression and regulation of PDGF-CC and PDGFR- $\alpha$ discussed above, and the prominent inflammatory infiltrates in renal fibrosis, all these mechanisms are plausible to take place during renal fibrosis. In most of the models studied herein, PDGF-CC inhibition or deficiency significantly reduced renal fibrosis. ${ }^{5}$ One might, therefore, expect to find a significantly better preserved amount of capillaries in mice with PDGF-CC neutralization, as was the case at a single time point after UUO in PDGF-CC-deficient mice. On the other hand, because of the general pro-angiogenic activity of PDGF-CC, neutralization or deficiency of PDGF-CC could have led to a stronger decline of interstitial capillaries in renal fibrosis. However, in all other models, we found similar numbers of capillaries between the groups. Taken together, these data suggest that the potential pro-angiogenic properties of endogenous PDGF-CC on PTC are negligible and are surpassed by its profibrotic properties.
The exact mechanisms triggering capillary dropout in renal fibrosis are not well understood. One hypothesis suggests that, despite hypoxia, dysbalance of angiogenic molecules in favor of anti-angiogenic factors results in microvascular rarefaction in kidney fibrosis. ${ }^{1,2,29}$ On PDGF$\mathrm{CC}$ neutralization, we found no indication of a consistent regulation of angiogenic factors, and found only a modelspecific down-regulation of pro-angiogenic $F g f 2$ in UUO and Vegfa in I/R (Figure 7). In addition, we previously found no regulation of $P d g f a$ or $P d g f b$ in the PDFG$\mathrm{CC}$-deficient or antibody-treated mice in the UUO model, whereas both PDGF receptors were down-regulated and exhibited reduced phosphorylation. ${ }^{30}$ These data argue against a compensatory up-regulation of pro-angiogenic or down-regulation of anti-angiogenic factors that could have masked the potential anti-angiogenic effects of PDGF-CC neutralization in our study. Our data showed that the effects of PDGF-CC neutralization on PTC loss and fibrosis were largely independent and did not correlate (Table 2). This, in turn, might suggest that renal microvascular rarefaction is a
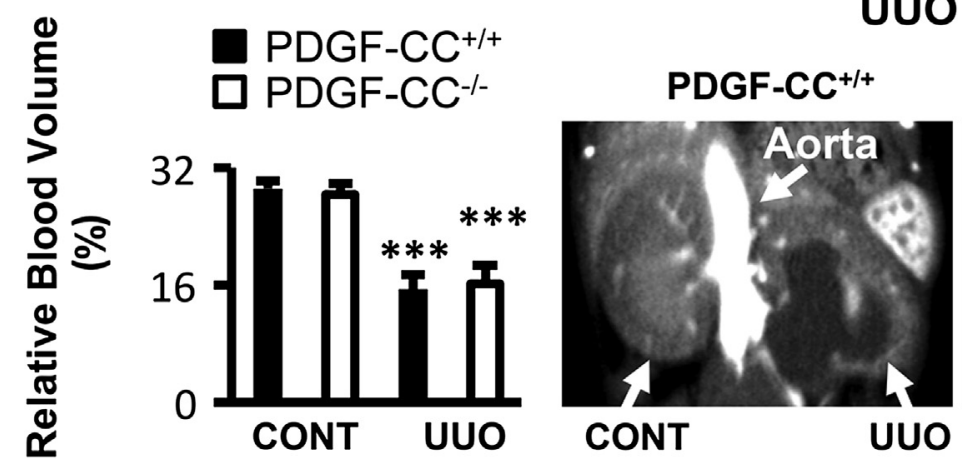

\section{UUO Day 5}

Figure 6 Deficiency of platelet-derived growth factor (PDGF)-CC does not alter renal relative blood volume (rBV), assessed by in vivo microcomputed tomography $(\mu \mathrm{CT})$. To noninvasively quantify the rBV in contralateral (CONT) and fibrotic kidneys in mice with unilateral ureteral obstruction (UU0) on day 5 , contrast-enhanced in vivo $\mu \mathrm{CT}$ was applied to PDGF-CC ${ }^{+/+}(n=3)$ and PDGF-CC ${ }^{-/-}(n=3)$ mice. Obstructed kidneys of both PDGF-CC ${ }^{+/+}$and PDGF-CC ${ }^{-/-}$ mice have significantly lower rBV values compared with contralateral kidneys $(P<0.001)$. No significant differences between PDGF-CC ${ }^{+/+}$and PDGF-CC ${ }^{-/-}$in either contralateral or obstructed fibrotic kidneys are observed (arrows pointing to the kidneys or aorta). Data are presented as means \pm SD. ${ }^{* * *} P<0.001$ versus respective CONT. 
A

Healthy baseline
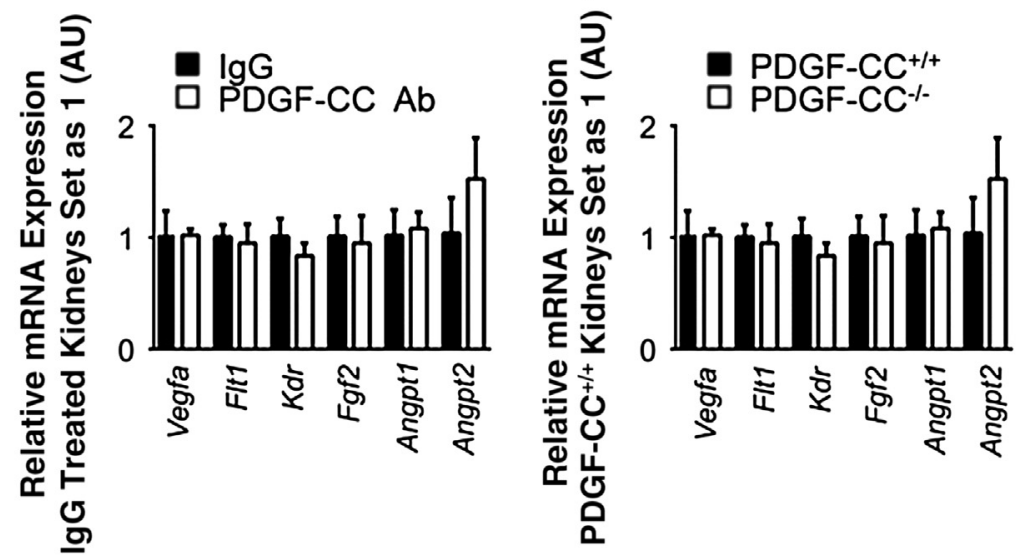

B

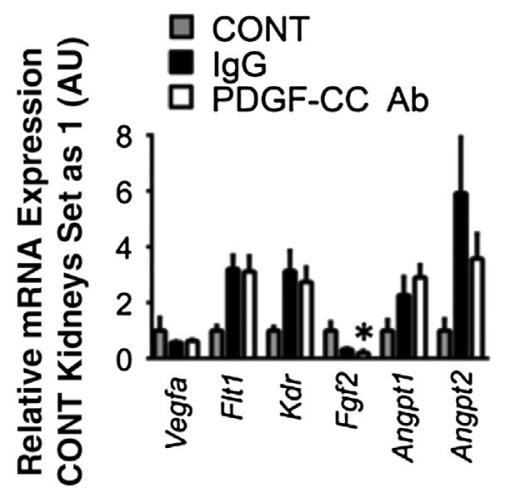

UUO day 5

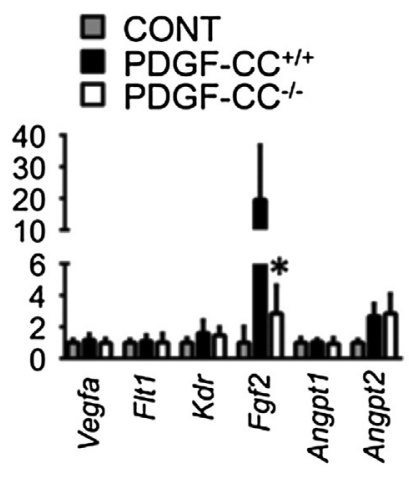

C

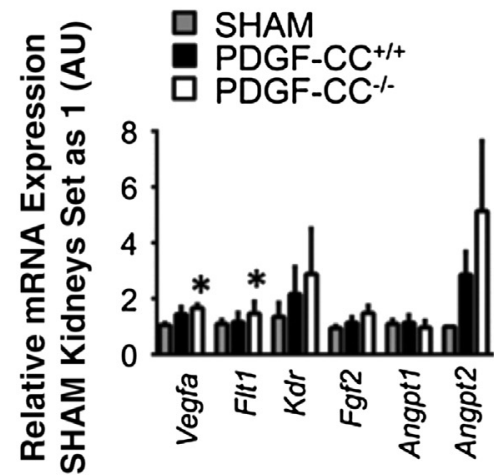

Figure 7 Transcript expression of angiogenesis-related molecules. A: In healthy mice, neither platelet-derived growth factor (PDGF)-CC antibody treatment nor genetic deficiency of PDGF-CC (PDGF-CC $\left.{ }^{-}\right)$) alters the relative gene expression of any of the analyzed genes $(n=4)$. B: $0 \mathrm{n}$ day 5 of unilateral ureteral obstruction (UU0), fibroblast growth factor (FGF)-2 is significantly lower in both PDGF-CC antibody-treated and in PDGF-CC ${ }^{-/-}$mice, compared with IgG-treated or PDGF-CC ${ }^{+/+}$mice, respectively $(n=4)$. All of the other genes show similar expression levels between the groups. C: $0 n$ day 21 of ischemiareperfusion injury (I/R), the expression levels of vascular endothelial growth factor (VEGF) and VEGF receptor (VEGFR)-2 are significantly higher in PDGF-CC ${ }^{-/}$

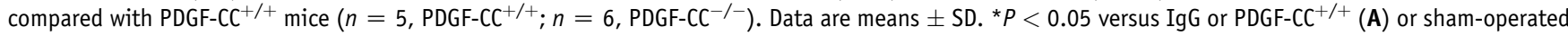
on kidneys (B). AU, arbitrary unit; CONT, contralateral.

process running in parallel with fibrosis and is rather a trigger for, than a consequence of, fibrosis. Taken together, all available data point to PDGF-CC as a selective factor influencing interstitial fibrosis, but not the associated processes such as PTC loss.

These findings might be kidney specific, because in the liver, PDGF-CC overexpression leads to liver fibrosis plus neoangiogenesis, followed by development of hepatocellular adenomas and carcinomas. ${ }^{10,31,32}$ The exact mechanisms of these divergent organ-specific effects in fibrosis, associated with capillary rarefaction in kidneys but neoangiogenesis in livers, are not yet clear. Differences in regulation of PDGFs and their receptors might be one possible explanation, as we have shown previously between fibrotic kidneys and livers. ${ }^{30}$ It might, however, be misleading to draw parallels, because in the mentioned liver studies, excessive PDGF-CC overexpression was used, whereas herein we interfered only with the endogenous PDGF-CC, which is more relevant.
Vessel leakage is associated with vascular dysfunction. Although the pro-angiogenic effects of VEGF are associated with the induction of leaky vessels, PDGF-CC promotes the formation of nonleaky capillaries. ${ }^{7,33}$ On the other hand, we found that tissue plasminogen activator-induced PDGF-CC activation significantly impaired the blood-brain barrier integrity during stroke. ${ }^{16,34}$ Our analyses of both healthy and fibrotic kidneys did not reveal any significant difference in microvascular leakiness between PDGF-CC-deficient and wild-type mice. This suggests that in the renal tubulointerstitium, PDGF-CC might not be a crucial factor influencing vascular leakage.

The pro-angiogenic effects of PDGF-CC are largely VEGF independent. $^{6-8,35}$ Although we found a slight increase in Vegfa and Flt1 mRNA expression in mice lacking PDGF-CC in the I/R model, in all other instances, our data did not reveal any regulation of VEGF or its receptors. On the other hand, we have shown previously in glomeruli that PDGF-CC induced another 
pro-angiogenic factor, FGF-2. ${ }^{11}$ Interestingly, fibrotic kidneys of mice with PDGF-CC deficiency or inhibition contained low Fgf2 mRNA levels compared with wild-type mice (Figure 7). As shown previously, this regulation of $F g f 2$ was only observed during disease, but not in healthy animals. ${ }^{11}$

Capillary rarefaction is a common finding in both experimental models and patients with renal fibrosis, in particular in the advanced stages. ${ }^{1,2,4}$ Capillary rarefaction in fibrosis was proposed to aggravate tissue hypoxia, thereby further driving renal fibrosis in a circulus vitiosus. ${ }^{1,2,4}$ It might also be an initiating factor in some instances (eg, in chronic vascular rejection of kidney allografts or in primary vascular diseases). Aggravation of capillary rarefaction during renal fibrosis could be detrimental for the progression of kidney diseases. In this respect, our data suggest that PDGF-CC neutralization does not significantly aggravate capillary rarefaction in experimental renal interstitial fibrosis and does not limit its therapeutic use as a novel potential antifibrotic treatment approach.

\section{Acknowledgments}

We thank Claudia Gavranic, Cherelle Timm, and Gerti Minartz for excellent technical assistance.

\section{Supplemental Data}

Supplemental material for this article can be found at http://dx.doi.org/10.1016/j.ajpath.2015.04.022.

\section{References}

1. Tanaka T, Nangaku M: Angiogenesis and hypoxia in the kidney. Nat Rev Nephrol 2013, 9:211-222

2. Kida Y, Tchao BN, Yamaguchi I: Peritubular capillary rarefaction: a new therapeutic target in chronic kidney disease. Pediatr Nephrol 2014, 29:333-342

3. Boor P, Floege J: Chronic kidney disease growth factors in renal fibrosis. Clin Exp Pharmacol Physiol 2011, 38:391-400

4. Boor P, Ostendorf T, Floege J: Renal fibrosis: novel insights into mechanisms and therapeutic targets. Nat Rev Nephrol 2010, 6:643-656

5. Eitner F, Bucher E, van Roeyen C, Kunter U, Rong S, Seikrit C, Villa L, Boor P, Fredriksson L, Backstrom G, Eriksson U, Ostman A, Floege J, Ostendorf T: PDGF-C is a proinflammatory cytokine that mediates renal interstitial fibrosis. J Am Soc Nephrol 2008, 19: 281-289

6. Hou X, Kumar A, Lee C, Wang B, Arjunan P, Dong L, Maminishkis A, Tang Z, Li Y, Zhang F, Zhang SZ, Wardega P, Chakrabarty S, Liu B, Wu Z, Colosi P, Fariss RN, Lennartsson J, Nussenblatt R, Gutkind JS, Cao Y, Li X: PDGF-CC blockade inhibits pathological angiogenesis by acting on multiple cellular and molecular targets. Proc Natl Acad Sci U S A 2010, 107:12216-12221

7. Li X, Kumar A, Zhang F, Lee C, Li Y, Tang Z, Arjuna P: VEGFindependent angiogenic pathways induced by PDGF-C. Oncotarget 2010, 1:309-314

8. Li X, Tjwa M, Moons L, Fons P, Noel A, Ny A, Zhou JM, Lennartsson J, Li H, Luttun A, Ponten A, Devy L, Bouche A, Oh H, Manderveld A, Blacher S, Communi D, Savi P, Bono F, Dewerchin M, Foidart JM, Autiero M, Herbert JM, Collen D, Heldin CH, Eriksson U, Carmeliet P: Revascularization of ischemic tissues by PDGF-CC via effects on endothelial cells and their progenitors. J Clin Invest 2005, 115:118-127

9. Cao R, Brakenhielm E, Li X, Pietras K, Widenfalk J, Ostman A, Eriksson U, Cao Y: Angiogenesis stimulated by PDGF-CC, a novel member in the PDGF family, involves activation of PDGFRalphaalpha and -alphabeta receptors. FASEB J 2002, 16:1575-1583

10. Campbell JS, Hughes SD, Gilbertson DG, Palmer TE, Holdren MS, Haran AC, Odell MM, Bauer RL, Ren HP, Haugen HS, Yeh MM, Fausto N: Platelet-derived growth factor C induces liver fibrosis, steatosis, and hepatocellular carcinoma. Proc Natl Acad Sci U S A 2005, 102:3389-3394

11. Boor P, van Roeyen CR, Kunter U, Villa L, Bucher E, Hohenstein B, Hugo CP, Eriksson U, Satchell SC, Mathieson PW, Eitner F, Floege J, Ostendorf T: PDGF-C mediates glomerular capillary repair. Am J Pathol 2010, 177:58-69

12. Boor P, Konieczny A, Villa L, Schult AL, Bucher E, Rong S, Kunter U, van Roeyen CR, Polakowski T, Hawlisch H, Hillebrandt S, Lammert F, Eitner F, Floege J, Ostendorf T: Complement C5 mediates experimental tubulointerstitial fibrosis. J Am Soc Nephrol 2007, 18: $1508-1515$

13. Yamaguchi I, Tchao BN, Burger ML, Yamada M, Hyodo T, Giampietro C, Eddy AA: Vascular endothelial cadherin modulates renal interstitial fibrosis. Nephron Exp Nephrol 2012, 120:e20-e31

14. Rogers DF, Boschetto P, Barnes PJ: Plasma exudation: correlation between Evans blue dye and radiolabeled albumin in guinea pig airways in vivo. J Pharmacol Methods 1989, 21:309-315

15. Patterson CE, Rhoades RA, Garcia JG: Evans blue dye as a marker of albumin clearance in cultured endothelial monolayer and isolated lung. J Appl Physiol 1992, 72:865-873

16. Su EJ, Fredriksson L, Geyer M, Folestad E, Cale J, Andrae J, Gao Y, Pietras K, Mann K, Yepes M, Strickland DK, Betsholtz C, Eriksson U, Lawrence DA: Activation of PDGF-CC by tissue plasminogen activator impairs blood-brain barrier integrity during ischemic stroke. Nat Med 2008, 14:731-737

17. Ehling J, Bartneck M, Wei X, Gremse F, Fech V, Möckel D, Baeck C, Hittatiya K, Eulberg D, Luedde T, Kiessling F, Trautwein C, Lammers T, Tacke F: CCL2-dependent infiltrating macrophages promote angiogenesis in progressive liver fibrosis. Gut 2014, 63:1960-1971

18. Ehling J, Theek B, Gremse F, Baetke S, Mockel D, Maynard J, Ricketts SA, Grull H, Neeman M, Knuechel R, Lederle W, Kiessling F, Lammers T: Micro-CT imaging of tumor angiogenesis: quantitative measures describing micromorphology and vascularization. Am J Pathol 2014, 184:431-441

19. Ehling J, Lammers T, Kiessling F: Non-invasive imaging for studying anti-angiogenic therapy effects. Thromb Haemost 2013, 109:375-390

20. Steegh FM, Gelens MA, Nieman FH, van Hooff JP, Cleutjens JP, van Suylen RJ, Daemen MJ, van Heurn EL, Christiaans MH, PeutzKootstra CJ: Early loss of peritubular capillaries after kidney transplantation. J Am Soc Nephrol 2011, 22:1024-1029

21. Fredriksson L, Nilsson I, Su EJ, Andrae J, Ding H, Betsholtz C, Eriksson U, Lawrence DA: Platelet-derived growth factor C deficiency in C57BL/6 mice leads to abnormal cerebral vascularization, loss of neuroependymal integrity, and ventricular abnormalities. Am J Pathol 2012, 180:1136-1144

22. Eitner F, Ostendorf T, Kretzler M, Cohen CD, Eriksson U, Grone HJ, Floege J: PDGF-C expression in the developing and normal adult human kidney and in glomerular diseases. J Am Soc Nephrol 2003, 14: $1145-1153$

23. Eitner F, Ostendorf T, Van Roeyen C, Kitahara M, Li X, Aase K, Grone HJ, Eriksson U, Floege J: Expression of a novel PDGF isoform, PDGF-C, in normal and diseased rat kidney. J Am Soc Nephrol 2002, 13:910-917

24. Boor P, Ostendorf T, Floege J: PDGF and the progression of renal disease. Nephrol Dial Transplant 2014, 29:I45-I54

25. Chen YT, Chang FC, Wu CF, Chou YH, Hsu HL, Chiang WC, Shen J, Chen YM, Wu KD, Tsai TJ, Duffield JS, Lin SL: Platelet-derived growth factor receptor signaling activates pericyte-myofibroblast 
transition in obstructive and post-ischemic kidney fibrosis. Kidney Int 2011, 80:1170-1181

26. Taneda S, Hudkins KL, Topouzis S, Gilbertson DG, Ophascharoensuk V, Truong L, Johnson RJ, Alpers CE: Obstructive uropathy in mice and humans: potential role for PDGF-D in the progression of tubulointerstitial injury. J Am Soc Nephrol 2003, 14: 2544-2555

27. Floege J, Hudkins KL, Seifert RA, Francki A, Bowen-Pope DF, Alpers CE: Localization of PDGF alpha-receptor in the developing and mature human kidney. Kidney Int 1997, 51:1140-1150

28. Floege J, Hudkins KL, Davis CL, Schwartz SM, Alpers CE: Expression of PDGF alpha-receptor in renal arteriosclerosis and rejecting renal transplants. J Am Soc Nephrol 1998, 9:211-223

29. Long DA, Norman JT, Fine LG: Restoring the renal microvasculature to treat chronic kidney disease. Nat Rev Nephrol 2012, 8:244-250

30. Martin IV, Borkham-Kamphorst E, Zok S, van Roeyen CR, Eriksson U, Boor P, Hittatiya K, Fischer HP, Wasmuth HE, Weiskirchen R, Eitner F, Floege J, Ostendorf T: Platelet-derived growth factor (PDGF)-C neutralization reveals differential roles of PDGF receptors in liver and kidney fibrosis. Am J Pathol 2013, 182: $107-117$
31. Campbell JS, Johnson MM, Bauer RL, Hudkins KL, Gilbertson DG, Riehle KJ, Yeh MM, Alpers CE, Fausto N: Targeting stromal cells for the treatment of platelet-derived growth factor C-induced hepatocellular carcinogenesis. Differentiation 2007, 75:843-852

32. Wright JH, Johnson MM, Shimizu-Albergine M, Bauer RL, Hayes BJ, Surapisitchat J, Hudkins KL, Riehle KJ, Johnson SC, Yeh MM, Bammler TK, Beyer RP, Gilbertson DG, Alpers CE, Fausto N, Campbell JS: Paracrine activation of hepatic stellate cells in plateletderived growth factor $\mathrm{C}$ transgenic mice: evidence for stromal induction of hepatocellular carcinoma. Int J Cancer 2014, 134:778-788

33. di Tomaso E, London N, Fuja D, Logie J, Tyrrell JA, Kamoun W, Munn LL, Jain RK: PDGF-C induces maturation of blood vessels in a model of glioblastoma and attenuates the response to anti-VEGF treatment. PLoS One 2009, 4:e5123

34. Su EJ, Fredriksson L, Schielke GP, Eriksson U, Lawrence DA: Tissue plasminogen activator-mediated PDGF signaling and neurovascular coupling in stroke. J Thromb Haemost 2009, 7 Suppl 1:155-158

35. Crawford Y, Kasman I, Yu L, Zhong C, Wu X, Modrusan Z, Kaminker J, Ferrara N: PDGF-C mediates the angiogenic and tumorigenic properties of fibroblasts associated with tumors refractory to anti-VEGF treatment. Cancer Cell 2009, 15:21-34 